Cell Research (1999), 9, 271-280

\title{
PSMA mimotope isolated from phage displayed peptide library can induce PSMA specific immune response
}

\author{
Zhu Zhong Yu ${ }^{1}$, Cui Ping Zhong ${ }^{2}$, Wei Feng $\mathrm{Xu}^{1}$, \\ Guo Mei Lin ${ }^{1}$, George Qw Ye ${ }^{3}$, Yong Yong Ji ${ }^{1}$, Bing \\ Sun ${ }^{1, *}, \mathrm{MING}_{\mathrm{YEH}}{ }^{1, *}$ \\ 1. Shanghai Institute of Cell Biology, Chinese Academy of \\ Sciences. \\ 2. Department of Histology, Shanghai Medical University. \\ 3. Yes Biotech Laboratories LTD, Canada
}

\begin{abstract}
Prostate-specific membrane antigen (PSMA) is a cell surface glycoprotein expressed predominantly in prostate secretory acinar epithelium and prostate cancer cells as well as in several extraprostatic tissues. Mouse monoclonal antibody 4G5 specific to the extracellular domain of PSMA was used to screen two phage displayed peptide libraries (9aa linear and 9aa cys library). Three 4G5-reactive phagotopes were identified. Sequence analysis of isolated clones demonstrated that the interaction motif "VDPA/SK" has high homology to 719-725aa on PSMA. Immunohistochemical staining of the prostate cancer sample with the PSMA-mimic phagotope (mimotope) immunized serum antibodies demonstrate that the mimotope isolated from the phage displayed peptide libraries can induce PSMA specific immune response in vivo.
\end{abstract}

Key words: PSMA, mimotope, phage displayed peptide library, immunohistochemistry.

\section{INTRODUCTION}

Prostate carcinoma is one of the most common cancer in men[1],[2]. The death rate from prostate carcinoma is also increasing in China. To improve this situation, new

* Corresponding author; E-mail: imceng@server.shcnc.ac.cn 
PSMA mimotope isolated from phage displayed peptide library

markers are needed for early and accurate staging and treatment as well as better means to follow disease progress. One such potential marker is prostate specific membrane antigen (PSMA).

PSMA is a type II membrane glycoprotein of $\mathrm{Mr} \sim 100,000$ with folate hydrolase-type and neuropeptidase-type activity[3-5]. PSMA is highly expressed in benign prostate secretory acinar epithelium, prostatic intraepithelial neoplasia and prostatic adenocarcinoma, and evidence suggests that PSMA expression is greastest in high-grade and hormone insensitive cancers. Given its membrane bound character, PSMA has been exploited as a marker for tumor detection and treatment with radioactive isotope or toxin labeled PSMA-specific antibodies. Especially, recent studies demonstrate that the monoclonal antibodies specific for the extracellular domain of PSMA are able to induce the internalization of PSMA[6]. Moreover, PSMA is also consistently expressed in the neovasculature of a wide variety of malignant neoplasms and maybe it is an effective target for Ab-based antineovasculature therapy[7].

With the development of phage displayed peptide library technology, it has been successfully applied to the epitope study and other relevant fields[8-10]. In this report, we employed the phage display peptide library to study the epitope recognized by mAb 4G5 and its immunogenicity to induce PSMA specific antibodies.

\section{MATERIALS AND METHODS}

\section{$m A b$}

Prostate membrane specific antigen specific monoclonal antibody 4G5 was from YES Biotech Laboratories Ltd, Canada. The antibody was generated from immunization with crude membrane extract of prostate carcinoma and screened out with synthesized 8-peptide ("ESKVDPSK" derived from the 716-723aa of PSMA sequence).

\section{Phage peptide libraries and bacteria strain}

Random phage peptide libraries expressing linear (pVIII 9aa)[11] or circular (pVIII 9aa Cys) [12] nonapeptides fused to pVIII of filamentous bacteriophage fd, wild type phage $\mathrm{f} 1$ and bacterial strain DH5aF' were all kindly provided by Dr. Paolo Monaci of IRBM (Istituto di Ricerche di Biologia Molecolare P. Angeletti SPA, Rome, Italy).

\section{Affinity selection}

Two rounds of affinity selection were performed as following, $200 \mu \mathrm{lmAb} 4 \mathrm{G} 5$ in coating buffer ( $50 \mathrm{mM} \mathrm{NaHCO}_{3}, \mathrm{pH} 9.6$ ) at $2 \mu \mathrm{g} / \mathrm{ml}$ was incubated in 96-well plate (Immuno plate Maxisorp, Nunc) at $4^{\circ} \mathrm{C}$ overnight, then blocked with blocking buffer $(1 \times$ PBS, 3\% BSA, $0.05 \%$ Tween $)$ at $37^{\circ} \mathrm{C}$ for $1.5 \mathrm{~h} .10^{11}$ wild type phage $\mathrm{f} 1$ in $200 \mu \mathrm{l}$ blocking buffer were added to the well and incubated at room temperature for $1 \mathrm{~h}$. The plate was washed extensively with PBST $(1 \times$ PBS, $0.1 \%$ Tween), then about $1 \times 10^{10}$ phages from either 9aa linear or 9aa cys circular peptide library in $200 \mu \mathrm{l}$ blocking buffer were added to the well and incubated at room temperature for $2 \mathrm{~h}$. After washing, the absorbed phages were eluted and neutralized with Tris-HCL as described[13]. The eluted phages were amplified by infecting DH5aF' and purified with 20\% PEG/2.5 M NaCl precipi tation. It can also be stored for immunoscreening. The purified phages were used for next round of affinity selection. 
ZHU ZY et al.

\section{Immunoscreening}

After two rounds of affinity selection, $\mathrm{DH} 5 \mathrm{aF}$ ' cells were infected with eluted phage at a multiplicity of infection (m.o.i.) of $10^{-3}$, the mixture was incubated at $37^{\circ} \mathrm{C}$ for $30 \mathrm{~min}$, then helper phage M13 K07 was added at a m.o.i. of 20-50, and incubated at $37^{\circ} \mathrm{C}$ for another $15 \mathrm{~min}$. The infected bacteria were centrifuged for $5 \mathrm{~min}$ at $3000 \mathrm{~g}$, the supernatant was discarded and bacteria pellet was washed three times in $1 \mathrm{ml}$ of LB medium to eliminate the non-absorbed phages. $100 \mu \mathrm{l}$ of the resuspended pellet with series of dilution $\left(10^{-3}, 10^{-4}, 10^{-5}\right)$ were plated on plates containing Ampicillin $(100 \mu \mathrm{g} / \mathrm{ml})$, Kanamycin $(50 \mu \mathrm{g} / \mathrm{ml})$ and IPTG $(30 \mu \mathrm{g} / \mathrm{ml})$. After incubation at $37^{\circ} \mathrm{C}$ overnight, the plates containing 200-400 separated clones (10 cm plate) were layered with nitrocellulose filters and marked with needle. The filter was took out immediately and blocked with blocking buffer ( $5 \%$ non-fat milk power, $1 \times$ PBS, $0.05 \%$ Tween-20, $0.05 \% \mathrm{~N}_{\mathrm{a}} \mathrm{N}_{3}$ ) at room temperature for two h. $10 \mu \mathrm{g}$ mAb preincubated with $25 \mu \mathrm{l}$ bacterial extract (prepared as described in Ref 13) and $25 \mu \mathrm{l}$ f1 Phage $\left(2.3 \times 10^{13} / \mathrm{ml}\right)$ in $5 \mathrm{ml}$ blocking buffer at room temperature for $1 \mathrm{~h}$, were then added to the blocked filters. Filter with mAb mixture was then incubated at room temperature for $1.5 \mathrm{~h}$ an $\mathrm{d}$ then extensively washed with washing buffer $(1 \times \mathrm{PBS}, 0.05 \%$ Tween-20). Then secondary antibody (alkaline phosphatase conjugated Goat anti-mouse Abs, Sigma) diluted to $1 / 5000$ in blocking buffer was incubated with the filter for $1.5 \mathrm{~h}$ at room temperature. The filters were then washed as above and developed by incubation with developing solution $(330 \mu \mathrm{g} / \mathrm{ml}$ nitro blue tetrazolium, $165 \mu \mathrm{g} / \mathrm{ml}$ 5-bromo-4-chloro-3-indolephosphate in 100 $\mathrm{mM}$ Tris $\mathrm{HCl}, 100 \mathrm{~m} \mathrm{M} \mathrm{NaCl}, 5 \mathrm{mM} \mathrm{MgCl}_{2}, \mathrm{pH}$ 9.6) at room temperature for $10 \mathrm{~min}$. Reaction was stopped by washing with water.

\section{ELISA}

In brief, multi-well plates (Immuno plate Maxisorp, Nunc) were coated overnight at $4^{\circ} \mathrm{C}$ with the mAb $4 \mathrm{G} 5$ at a concentration of $2 \mu \mathrm{g} / \mathrm{ml}$ in $50 \mathrm{mM} \mathrm{NaHCO}_{3} \mathrm{pH} 9.6$. After washing several times with PBS $/ 0.05 \%$ Tween-20 (PBST), plates were incubated at $37^{\circ} \mathrm{C}$ for 60 min with ELISA blocking buffer (5\% non-fat dry milk in PBST). $4 \times 10^{9}$ sample phages were diluted in $100 \mu$ l blocking buffer and then added to each well and allowed to bind for $1 \mathrm{~h}$ at $37^{\circ} \mathrm{C}$. The equal amount of wild type phage was used as a negative control. Plates were then washed with PBST and $100 \mu \mathrm{l} /$ well of goat anti-mouse IgG HRP conjugated antibodies (Sigma, 1/5000 dilution in ELISA blocking buffer) were added. After incubation for $1 \mathrm{~h}$ at room temperature, plates were then washed and developed by adding $100 \mu \mathrm{l}$ substrate TMB buffer and incubated at $37^{\circ} \mathrm{C}$ in dark for $15 \mathrm{~min}$. Optical density was measured in an ELISA reader at $450 \mathrm{~nm}$.

\section{Competitive ELISA}

96-well ELISA plates were coated with $1 \times 10^{9}$ phage/well of $\mathrm{f} 1$ or three phage clones. Fixed amount of immune serum (1:2700 dilution) is incubated in each well with increasing amount of competitor f1 (from 0 to $1.5 \times 10^{9}$ ). After extensively washing, the HRP conjugated secondary antibody (goat anti-mouse IgG) was added. Following development, the optical density value was read at $450 \mathrm{~nm}$.

\section{DNA sequencing}

Single stranded DNA of the positive clones was extracted from the amplified phages using DNA purification kit according to the instructions (Promega). Sequencing was performed by the Sanger dideoxy method with T7 sequencing kit (Pharmacia) according to the instructions.

\section{Immunization of mice with selected phage}

The identified positive phage clones were amplified in $\mathrm{DH} 5 \mathrm{aF}$ ' and purified by $\mathrm{PEG} / \mathrm{NaCl}$ precipitation. Then the phages were resuspended in $1 \times \mathrm{PBS}$ at a concentration of $5 \times 10^{12}$ phage particles $/ \mathrm{ml}$. Ten to twelve-week old male C57BL/6 mice were immunized by i. p. $250 \mu$ l of positive phage clones emulsion (1:1 with CFA for the primary injection, IFA for the boost injections), 
PSMA mimotope isolated from phage displayed peptide library

using wild type phage $\mathrm{f} 1$ as control. The immunization was performed at week 0,4 and 7 and bled at days 10 after second and third injection.

\section{Absorbing immunized serum with wild type phage f1}

The immune serum was absorbed with wild type f1. $20 \mathrm{ml}$ serum was diluted $1 \mathrm{ml}$ and mixed with $1 \mathrm{ml}$ PBS containing $1 \times 10^{13} \mathrm{f} 1$ phage particles. Then the mixture was centrifuged at $200,000 \mathrm{~g}$ for $2 \mathrm{~h}$, The supernatant was collected and used in immunohistochemical staining at 1:200 dilution.

\section{Immunohistochemical staining}

All the slides of prostate cancer, lung cancer, stomach cancer and colon cancer were prepared routinely. Endogenous peroxidase activity was quenched by $30 \mathrm{~min}$ incubation in $3 \%$ hydrogen peroxide. After washing, the slides were blocked with 5\% normal goat serum for $30 \mathrm{~min}$. The f1absorbed mimotope immunized serum diluted in 1:200 were added to the slides as first layer antibody and incubated at $4{ }^{\circ} \mathrm{C}$ overnight. Immunized serum with wild type phage $\mathrm{f} 1$ was used as negative control. After washing extensively with $1 \times$ PBS $0.05 \%$ Tween-20, HRP conjugated goat anti-mouse IgG was added and incubated at $37{ }^{\circ} \mathrm{C}$ for $1 \mathrm{~h}$. After washing with PBS tween, the slides were developed by adding the substrate DAB and $\mathrm{H}_{2} \mathrm{O}_{2}$ according to the manufacture' $\mathrm{s}$ instructions. The reaction was stopped by washing with water. Slides were counterstained lightly with Harris hematoxylin, dehydrated through a graded series of ethanol to xylene and coverslipped with permount.

\section{RESULTS}

\section{Affinity selection}

Two rounds of affinity selection were performed before the immunoscreening. After each round of affinity selection, the percentage of the blue clones was calculated from every eluted pool of phage, and the titer of the phage was counted (Tab 1). From both libraries, the increase of the phage titer and percentage of blue clones were observed, indicating the enrichment of specific ligand during the affinity selection. The increase of phage titers was in parallel with an increase of phages binding to 4G5 in ELISA. And low binding was observed with equal amounts of wild-type phage f1 (Fig 1).

Tab 1. Eluted phage titer after affinity selection with mAb 4G5.

\begin{tabular}{|c|c|c|c|c|}
\hline \multirow{3}{*}{ Phage library } & \multicolumn{3}{|c|}{ Affinity selection } & \\
\hline & \multicolumn{2}{|c|}{ Round 1} & Round 2 & \multirow[b]{2}{*}{ Titer } \\
\hline & Percentage of blue clones ${ }^{1}$ & Titer & Percentage of blue clones & \\
\hline 9aa library & $45 \%$ & $1.4 \times 10^{4}$ & $83 \%$ & $2.3 \times 10^{6}$ \\
\hline 9aa cys library & $42 \%$ & $8.4 \times 10^{3}$ & $76 \%$ & $6.7 \times 10^{5}$ \\
\hline \multicolumn{5}{|c|}{$\begin{array}{l}\text { 1. Percentage of blue clones can be used as a parameter indicating the enrichment of functional } \\
\text { phage peptide[11]. }\end{array}$} \\
\hline
\end{tabular}

\section{Immunoscreening and sequence analysis.}

After the second round of affinity selection, the eluted phages were plated on the LB plates. After the development of the filters, for the 9aa library, 10\% of the clones on the 
filter were positive, while for the pool from 9aa cys library, only $1 \%$ of the clones were positive. 9 positive clones from 9aa library and 2 clones from 9aa cys library were randomly picked out. After amplification and purification with $\mathrm{PEG} / \mathrm{NaCl}$ precipitation, ELISA was performed. All the clones showed specific binding to the mAb (Fig 2). DNA sequencing results indicate the $\mathrm{c} 1, \mathrm{c} 3$ and $\mathrm{c} 7$ are from a single clone, which is referred as clone No. $1 ; \mathrm{c} 2, \mathrm{c} 4, \mathrm{c} 5, \mathrm{c} 6, \mathrm{c} 8$ and $\mathrm{c} 9$ are from another single clone, which is referred as clone No. 2; cc1 and cc2 are also from one single clone, which is referred as clone No. 3. Sequence analysis of the three clones shows high homology with the 719-725aa of PSMA (Tab 2). From the sequence analyses of all the isolated clones, combining with their reactivity with the mAb, the conserved motif sequence is "VDPA/SK", which is very close to the PSMA sequence from 719-725aa in extracellular part.

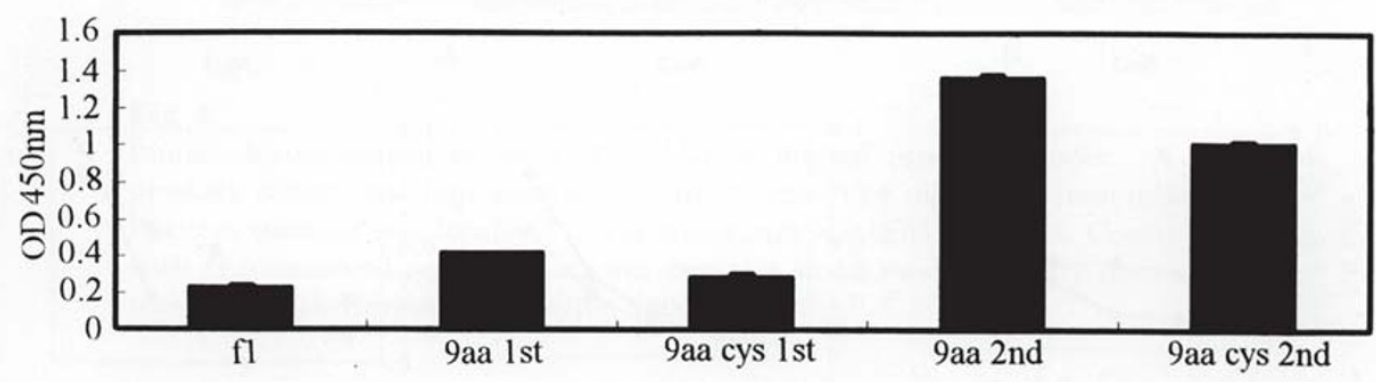

Fig 1.

ELISA results of the binding activity of the selected phage pool after amplification from two rounds of affinity selection

9aa 1st, 9aa 2nd and 9aacys 1st and 9aacys 2nd refer to the amplified phage pool after first round and second round selection from 9aa linear peptide library and 9aa cys circular library respectively. Equal amount of f1 was used as control.

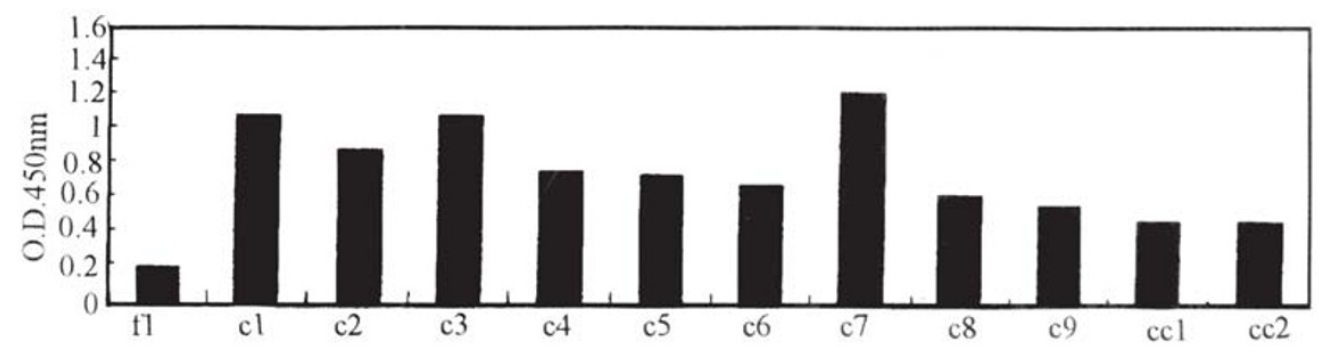

Fig 2.

ELISA results of the binding activity of single clones identified from 9aa and 9aa cys library after immunoscreening. Clones c1-c9 were from 9aa library, clones cc1 and cc2 were from 9aa cys library, and $\mathrm{f} 1$ was used as control. 
PSMA mimotope isolated from phage displayed peptide library

Tab 2. Sequence analysis of the isolated clones

\begin{tabular}{|c|c|}
\hline PSMA peptide 716-725aa & E S K V D P S K A W \\
\hline No 1 (x3) from 9aa library & V D P G K Y N K Y \\
\hline No 2 (x6) from 9aa library & E G P A K G F K L \\
\hline No 3 (x2) from cys library & G C Y E A P S K A A K C \\
\hline
\end{tabular}

\section{Immunogenic mimicry of PSMA epitope}

Three phage clones and wild type $\mathrm{f} 1$ were used to immunize the C57BL/6 mice respectively. Ten days after the third immunization, all the immunized mice were bled, and ELISA was performed to identify the titers of the immunized serum. Competitive ELISA was employed to analyze the specificity of the immunized serum (Fig 3).

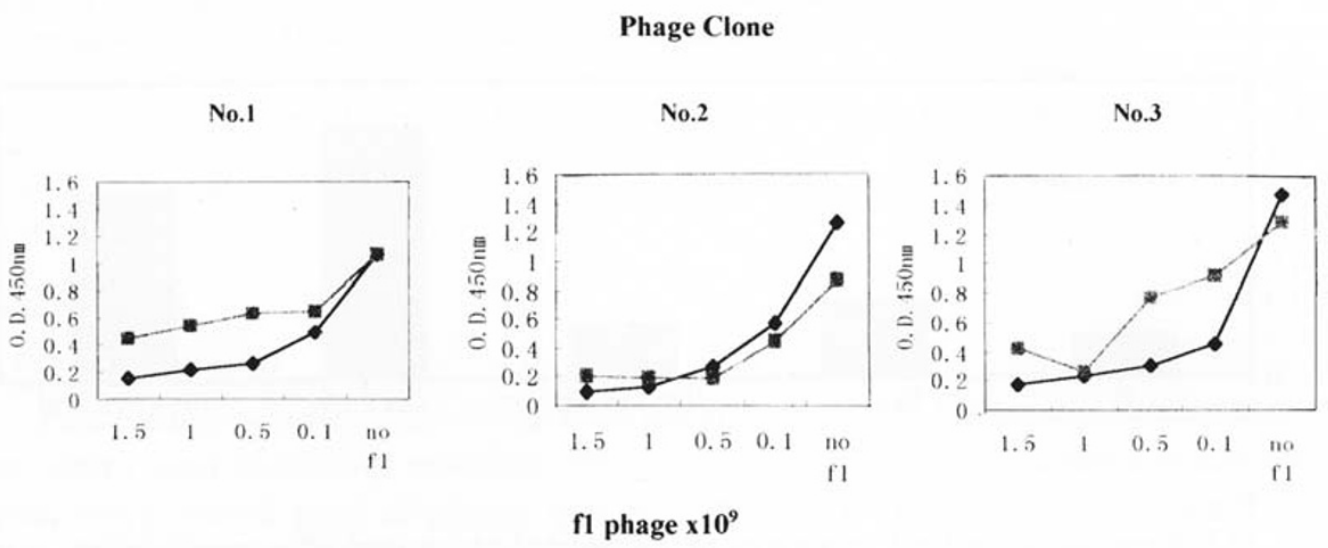

Fig 3.

Results of competitive ELISA, testing the specificity of phage-immunized serum.

(- - coated with wild type phage f1).

(- - coated with phage clone $1,2,3$ respectively )

When the f1-reactive antibodies in the phage peptide immunized serum were sufficiently absorbed with $\mathrm{fl}$, and if the absorbed serum still has significant reactivity to the corresponding phagotope, it indicates the existence of phage displayed peptide specific antibodies in the immunized serum. In comparison of the reactivity of all three clones, immunized serum from both clone No.1 and clone No.3 showed significnt phagotope specificity but result from No.1 clone seemed to be more consistently and was selected to check its specificity to PSMA on the slides with immunohistochemical staining, and f1 immunized serum was used as negative control. At the same time, several other human cancer samples such as lung cancer, colon cancer and stomach cancer are also tested and no positive staining was observed on the epithelial cells of these samples (Data not shown). However, positive staining was localized on the malignant epithelial cells of human pros- 
ZHU ZY et al.

tate cancer tissue, while, no positive staining was observed on the f1-immunized serum stained slides (Fig 4).

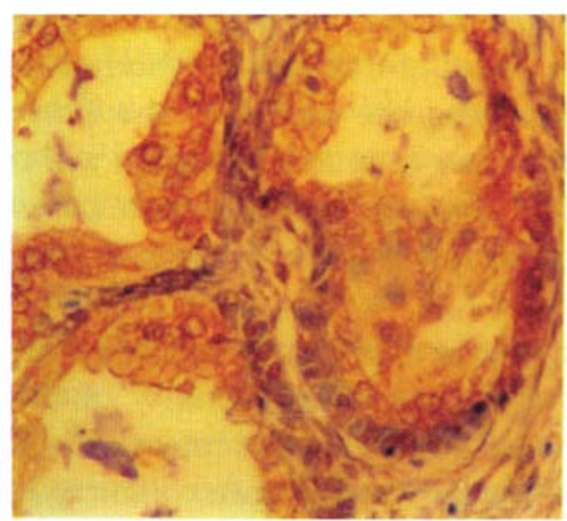

$\mathbf{A}$

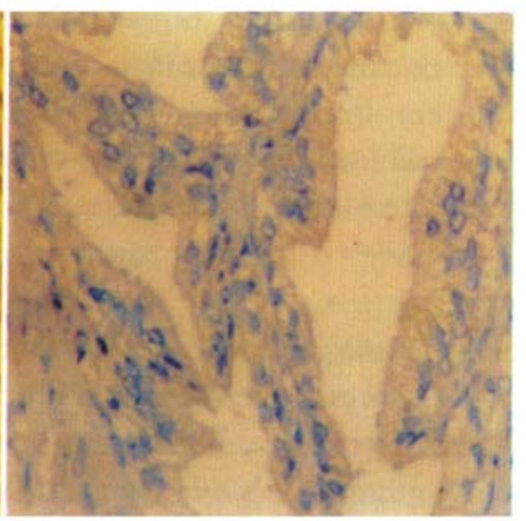

B

\section{Fig 4.}

Immunohistochemical staining of PSMA in human prostate cancer. A. Slide of prostate cancer was immunostained with $\mathrm{f} 1$ absorbed mimotope-immunized serum. Positive staining was localized to the malignant epithelial cells. B. Control staining with f1-immunized serum serum was negative in all cases. Lightly counterstaining was done with Harris hematoxylin. $(400 \times)$.

\section{DISCUSSION}

In our experiment, we did not perform the biopanning with the mixture of 9aa linear and 9aa cys peptide library. Since in many cases, when these two libraries were mixed together in the selection, only the linear peptide clones can be isolated from the last identification (unpublished data, Dr. Paolo Monaci), possibly because the growth and amplification efficiency of the linear phage peptide clones is much higher than that of the circular phage peptide clones. After several rounds of elution and amplification, the ratio of the linear phage peptide clones will dramatically increase in the selected pool, while the positive clones from circular phage peptide library will be lost at last. From our experimental results we can see the enrichment of the positive linear phage peptide is much faster than that of the circular phage peptide library.

Generally, many researchers perform three rounds or more of biopanning in the affinity selection before picking out single clones for identification. However, we just performed two rounds of affinity selection which is sufficient for the isolation of positive clones. In fact, how many rounds of affinity selection is appropriate depend on the aim of the selection and the target used for the selection. In our case, we used the purified $\mathrm{mAb}$ as the target for affinity selection. The enrichment of target-specific phage peptide with $\mathrm{mAb}$ is much faster than that of the selection with complicated target such as serum 
PSMA mimotope isolated from phage displayed peptide library

antibodies. Thus, less rounds of selection is sufficient for the isolation of positive clones. On the other hand, the aim of our experiment is the epitope location of the PSMA. Generally, only 4-6 amino acids are critical for the interaction between the antigen and antibody. In this case, trying to pick out the interaction motif from a series of different antibody-reactive phage peptides is very important. Therefore, keeping the variety of the isolated positive clones is critical for this point. However, higher rounds of selection will result in the enrichment of the dominant clone (Dr. Li Hua, personal communication). On the contrary, we have to identify many more clones in order to keep the variety of the positive clones.

After the immunization of mice with three mimotopes displayed on phage, we did not use the synthesized peptide to test the binding activity of the mimotope immunized serum antibodies, because to some extent, the interaction between the antibody and phage displayed peptide depends on the peptide's micro environment which is provided by the phage particle during the affinity selection, in this case the free peptide will loose the conformation which can be recognized when it was displayed on phage particle[14]. Therefore, we employed the competitive ELISA to test the mimotope specificity of immune serum. From the competitive ELISA results, we observed that both clone No.1 and No.3 induced significant mimotope specific response. Many researchers have demonstrated that filamentous phage is an excellent immunogen. The easily induced immune response in mice is T-cell dependent and undergoes class switching from IgM to IgG[14]. However, the induction of mimotope-specific antibodies is a much more difficult process and varies considerably from one mimotope to another mimotope. This may be reasonable since the immune system can differentiate different antigens and produces very different responses.

Comparing the conserved sequence motif "VDPA/SK" derived from No.1, 2 and 3 phage clones with the PSMA sequence "ESKVDPSK" which was used in the screening process of mAb 4G5, we found they are of high homology, and the "VDPSK" may play a major role in the interaction between the PSMA and mAb 4G5. In addition, the homology of the peptide to the real antigen may be further promoted through an in vitro evolution strategy (Zhu et al submitted[15]). From our results it showed that if we have not any data about the $\mathrm{mAb}$ reactive antigen, the deduced peptide or oligonucleotide from the interaction motif can be used as a probe for the identification of the mAb specific antigen. In fact, since the establishment of monoclonal antibody technology, many monoclonal antibodies have been developed which are specific for many different antigens. However, many of these mAb-specific antigens have not been identified yet, such as many cell specific mAbs. In this case, in addition to its successful and extensive application in the epitope mapping of antigen, phage displayed peptide library technology can be a very effective way worthy to be tried for the identification of antigen, even this strategy is limited to the identification of the linear epitope at present.

Our experimental results have demonstrated that 4G5 specific epitope is located at 719723aa of PSMA, which belongs to extracellular of PSMA. The highly prostate-specific and membrane-bound character of PSMA makes it an ideal target for clinical diagnostic 
and therapeutic applications in the treatment and management of prostatic carcinoma. Especially, the antibody induced internalization of PSMA which has been identified recently possibly indicate the biological function of PSMA in vivo. Evidently, the characterization of this PSMA extracellular domain specific mAb will be very useful in the antibody targetting strategy for the diagnosis and therapy of prostate cancer.

Recent researches showed PSMA not only overexpressed in prostate cancer, but also in the neovasculature of a variety of malignant neoplasms, indicating that PSMA may play an important role in the genesis and devlopment of other cancer. The mimotopes screened out presumably might be used as vaccine to induce PSMA specific immune responses in vivo, and maybe hopefully inhibit the development of the cancer.

\section{ACKNOWLEDGEMENTS}

This work was supported by the Special Support Fund Stz-2-06 from the Chinese Academy of Sciences and also supported by World Laboratory. We thank Prof. Ricardo Cortese, Dr. Paolo Monaci and Dr. Franco Felici of IRBM, Italy for providing peptide libraries and Dr Minenkova Olga for helpful discussion and advice. We also thank Dr YangJin, Dr. Tao QinHua, Yao Gang, and Huang Junyu for providing specimen slides.

\section{REFERENCES}

[1] Murphy GP, Elgamal AA, Su SL, Bostwick DG, Holmes EH. Current evaluation of the tissue localization and diagnostic utility of prostate specific membrane antigen. Cancer 1998; 83(11):2259-69. Review.

[2] Zhang S, Zhang HS, Reuter VE, Slovin SF, Scher HI, Livingston PO. Expression of pontential target antigens for immunotherapy on primary and metastic prostate cancers. Clin Cancer Res 1998; 4:295302.

[3] Lopes D, Davis WL, Rosenstraus MJ, Uveget AI, Gilman SC. Immunohistochemical and pharmacokinetic characterization of the site-specific immunoconiugate CYT-356 derived from anti-prostate monoclonal antibody 7E11 C5. Cancer Res 1990; 50:6423-9.

[4] Pinto JT, Suffoletto BP, Berzin TM et al. Prostate specific membrane antigen: a novel folate hydrolase in human prostatic carcinoma cells. Clin Cancer Res 1996; 2:1445-51.

[5] Carter RE, Feldman AR, Coyle JT. Prostate-specific membrane antigen is a hydrolase with substrate and pharmacologic characteristica of a neuropeptidase. ProcNatl Acad Sci USA 1996; 93:749-53.

[6] Liu H, Rajasekaran AK. Moy P et al. Constitutive and antibody-induced internalization of prostatespecific membrane antigen. Cancer Res 1998; 58(18):4055-60.

[7] Chang SS, Reuter VE, Heston WDW, Bander NH, Grauer LS, Gaudin PB. Five different anti- prostatespecific membrane antigen (PSMA) antibodies confirm PSMA expression in tumor-associated neovasculature. Cancer Res 1999; 59(13):3192-7.

[8] Cortese R, Monaci P, Luzzago A et al. Selection of biolocically active peptides by pliage display of random peptide libraries. Current Opinion in Bioteciniology 1996; 7:616-21.

[9] Cortese R, Felici F, Galfre G, Luzzago A, Monaci P, Nicosia A. Epitope discovery using peptide libraries displayed on phage. Trends in Biotech. 1994; 12:262.

[10] Meola A, Deirnastro P, Monaci P et al. Derivation of vaccines from mimotopes. Immunological properties of HBsAg mimotopes displayed on filamentous phage. J Immunol 1995; 154:3162.

[11] Felici F, Castagnoli L, Musacchio A, Jappelli R, Cesareni G. Selection of antibodies ligands from a large 
PSMA mimotope isolated from phage displayed peptide library

library of oligopeptides expressed on a multivalent exposition vector. J Mol Blol 1991; 222:301.

[12] Luzzago A, Felici F, Tramontano A, Pessi A, Cortese R. Mimicking of discontinuous epitopes by phage displayed peptides, I. Epitope mapping of human $\mathrm{H}$ ferritin using a phage library of constrained peptides. Gene 1993; 128:51.

[13] Prezzi C, Nuzzo M, Meola A et al. Selection of antigenic and immunogenic mimics of hepatitis C virus using sera from patients. J Immunol 1996; 156(11):4504-13.

[14] Galfre G, Monaci P, Nicosia A, Luzzago A, Felici F, Cortese R Immunization with phage-displayed mimotopes. Methods Enzymol 1996; 267:109-15.

[15] Zhu ZY, O Minenkova, F Bellintani et al. “In vitro evolution” of ligands for HCV-specific serum antibodies. (Submitted for publication)

Received Nov-13-1999. Revised Nov-19-1999. Accepted Nov-24-1999. 